\title{
Pandemic influenza and Canada's children
}

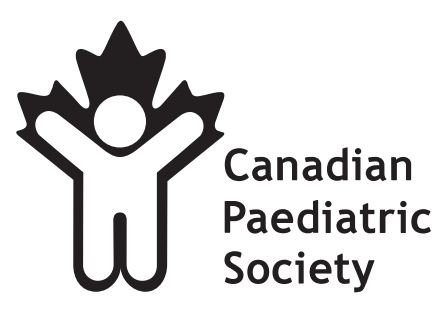

to spread around the world in a matter of months. The first peak of illness is expected to occur two to four months later, and the peak of mortality is expected within one month of the peak in illness. The Public Health Agency of Canada has estimated the impact of disease using published models that are based on the epidemiology of previous pandemics and interpandemic influenza $(1,2)$. In these models, $15 \%$ to $35 \%$ of the Canadian population (4.5 to 10.6 million citizens) will become clinically ill, with between 2.1 and five million requiring outpatient care, between 34,000 and 138,000 Canadians requiring hospitalization, and between 11,000 and 58,000 deaths. The age distribution of illness in the next pandemic cannot be predicted; with the exception of the 1918 pandemic, older persons - rather than children and youth have had the highest mortality rates (3). Some general assumptions accepted as important for contingency planning for the next influenza pandemic are as follows:

- there will be widespread shortages of personnel to provide essential services and health care;

- health care facilities will be overwhelmed;

- there will be an insufficient supply of material resources in health care facilities, including vaccines and antivirals; and

- because of widespread infection, assistance from other provinces or countries is unlikely to be available.

Clearly, pandemic influenza will have a broad societal impact beyond its effect on the health care system.

\begin{tabular}{|c|c|c|}
\hline $\begin{array}{l}\text { Communicability } \\
\text { of novel } \\
\text { influenza virus }\end{array}$ & Risk of transmission & $\begin{array}{c}\text { Pandemic } \\
\text { alert } \\
\text { phase }\end{array}$ \\
\hline Interpandemic phase: & Low risk of human cases & 1 \\
\hline $\begin{array}{l}\text { new virus in animals, } \\
\text { no human cases }\end{array}$ & Higher risk of human cases & 2 \\
\hline \multirow{3}{*}{$\begin{array}{l}\text { Pandemic alert: } \\
\text { new virus causes } \\
\text { human cases }\end{array}$} & $\begin{array}{l}\text { No or very limited human-to-human } \\
\text { transmission }\end{array}$ & 3 \\
\hline & $\begin{array}{l}\text { Evidence of increased human-to-human } \\
\text { transmission }\end{array}$ & 4 \\
\hline & $\begin{array}{l}\text { Evidence of significant human-to-human } \\
\text { transmission }\end{array}$ & 5 \\
\hline Pandemic & $\begin{array}{l}\text { Efficient and sustained human-to-human } \\
\text { transmission }\end{array}$ & 6 \\
\hline
\end{tabular}

Data from reference 7 transmitted and sustain infection in humans, it is expected

Correspondence: Dr Joanne Langley, Division of Infectious Diseases, Department of Pediatrics and Infection Prevention and Control Services, IWK Health Centre, 5850 University Avenue, Halifax, Nova Scotia B3K 6R8. Telephone 902-470-8498, fax 902-470-7232, e-mail joanne.langley@dal.ca 


\section{WILL PANDEMIC INFLUENZA AFFECT CHILDREN DIFFERENTLY THAN INTERPANDEMIC INFLUENZA?}

The clinical manifestations and population epidemiology of a novel strain of influenza are impossible to predict. Whereas seasonal or 'interpandemic influenza' causes $1 \%$ to $20 \%$ of the population to become ill each year, the clinical manifestations are fairly predictable. Younger children may have fever with upper respiratory tract infection, febrile seizures, cough, diarrhea, a sepsis-like picture or pneumonia. Older children may complain of headache, myalgia, sore throat or cough. In children with cardiac or pulmonary disease, exacerbation of their underlying illness may occur.

The avian influenza outbreak in Asia between 2005 and 2006 has been characterized by a preponderance of severe illness in children (4). These children have likely been infected by domestic birds during close contact. The mortality rate in all infected persons has been high. Unusual disease patterns have been observed in children, such as predominately gastrointestinal or central nervous system illness, in addition to presentations with respiratory signs and symptoms. While the clinical manifestations of the influenza virus strain that causes the pandemic cannot be predicted, influenza-like respiratory illness is likely to be part of the clinical spectrum.

Beyond the possible different epidemiology of a novel strain of influenza in children, there are also special considerations for preparing for and responding to the health care needs of children during pandemic influenza with regard to vaccines, antivirals and health care delivery. Because children have more limited exposure to influenza antigens, through either infection or immunization, than do adults, they may have less robust immune responses and require different vaccine schedules than those for older persons. The current antivirals available for chemoprophylaxis and treatment of influenza cannot be used in all paediatric age groups. Oseltamivir is not approved for use in children younger than one year and more information is required about its safety in this age group. Furthermore, the liquid formulation of oseltamivir, unlike the adult capsule formulation, has a shorter half-life and is thus less suitable for stockpiling. A second antiviral, zanamivir, is delivered as an inhaled medication and therefore would be unlikely to be used in children younger than five or six years, or in the cognitively impaired.

Health care delivery to young children requires more direct physical contact than that to older persons, and higher staffto-patient ratios are often required to ensure patient safety. Shortages of staff may therefore disproportionately affect the quality of child health care delivery. Parents or other family caregivers are active participants in their children's care at home and while hospitalized. Illness in these caregivers, as is expected to occur during a pandemic, will have direct consequences for the health of children and youth. As well, schools may be closed either due to illness, as a public health measure, or to use school facilities for other activities, such as triage centres or influenza clinics. This will challenge the abilities of health care workers with young families to provide for them and continue their work responsibilities.

\section{WHAT IS CANADA'S PLAN?}

Preparation for a pandemic includes activities before, during and after the event. A series of 'preparedness levels' have been defined by the WHO (Table 1) that describe the level of alert for pandemic influenza virus activity. Each level has a corresponding set of responsibilities for nations and the WHO. The Canadian Pandemic Influenza Plan (2) provides a framework for planning key emergency response activities, and was developed over many years in collaboration with multiple stakeholders, including representatives from the Canadian Paediatric Society. The overall goal of Canada's Plan is first, to minimize serious illness and overall deaths, and second, to minimize societal disruption among Canadians as a result of an influenza pandemic (5). The plan follows the general principles of emergency response planning and has sections on preparedness, response and recovery. It is intended to facilitate local, regional and national activities in surveillance, vaccine programs, use of antivirals, health services including clinical care guidelines and tools, emergency services, public health measures, communications, management of mass fatalities, use of nontraditional care sites, and infection control and occupational health guidelines. Information on self-care for parents caring for their children and themselves is also provided. The response section of the Plan also addresses the operational activities for an effective national response, including essential federal, provincial and territorial coordination.

The Canadian Pandemic Influenza Plan includes prioritization lists for vaccines and antivirals in the event of insufficient supply during the pandemic. First, it is important to note that the government has stated its goal: to provide vaccines for all Canadians. The prioritization list will be used if there is there is insufficient supply. Second, the plan is based on what is known about the epidemiology and disease burden of past epidemics. The intent is for the Plan to change (eg, prioritization of certain populations, such as children, for treatment or prophylaxis) if the epidemiology or disease burden of pandemic influenza is different than that of past epidemics. For example, if children are predominately affected, it is expected that they will suffer the most morbidity and mortality, and will be high on the prioritization list.

\section{HOW CAN PAEDIATRICIANS AND OTHER PHYSICIANS PREPARE FOR AN INFLUENZA PANDEMIC?}

Paediatricians and other physicians must consider their own health, preparing their patients and families, and consider how they will change their practice profile during the pandemic.

\section{Personal health}

Maintaining healthy, active living, especially avoiding cigarette smoking, will increase the chances of avoiding serious morbidity with influenza. Developing the habit of using regular personal protective precautions in one's daily work 
(eg, hand hygiene before and after each completed patient contact, wearing surgical masks to prevent exposure to respiratory droplets when caring for those with respiratory infections, and keeping one's hands away from the eyes and nose during patient care to prevent self-inoculation) will increase the chances of preventing influenza transmission during interpandemic and pandemic periods. Vaccine specific against the pandemic strain of influenza is not expected to be available for three to five months after the pandemic onset. Health care workers are considered a priority for receipt of vaccine in the Canadian Pandemic Influenza Plan because they will be needed to care for the sick. The Canadian Paediatric Society is not recommending that individual physicians stockpile antivirals for personal use. Personal emergency planning is also recommended. More information can be obtained through Public Safety and Emergency Preparedness Canada (6).

\section{Preparing patients and families}

Accessibility to health care will be greatly reduced during an influenza pandemic. Families of both healthy and chronically ill children will therefore need to prepare for self-care, care by nonspecialist providers, and reduced access to ambulatory, home care and hospital services. Many jurisdictions have developed algorithms for triage of patients to home and to nontraditional care sites, such as 'flu clinics', with only the most severely ill persons being sent to hospital. Use of emergency rooms for all but urgent illness will be discouraged. Paediatricians and other physicians need to play a central role in helping families plan for these circumstances and adapt their expectations about service during a time of social disruption. Because schools and out-of-home child care centres may be closed during the pandemic, paediatricians and other physicians should advise working parents to consider in advance their options for alternative child care arrangements.

\section{Planning what aspects of your practice you will continue} during a pandemic

This type of planning, called 'business continuity planning', involves identifying the activities you are engaged in as a paediatrician, and deciding which ones are the highest priority to be continued during a pandemic. Pandemic influenza is expected to affect all strata of society, including health care providers. Paediatricians and other physicians - whether in solo, community practices or in group, subspecialty, hospitalbased settings - need to consider their core activities, prioritize them and plan how these core activities will take place when up to $35 \%$ of the workforce is absent. Paediatricians and other physicians may also be called on, or required, to work in different settings than those in which they currently practice to rationalize scarce human resources across the health care system. They may also be needed to train nontraditional site personnel in caring for children, and to assist in planning and allotting scarce resources.

Advocating for the needs of children and youth

In Canada and around the world, plans are in progress to prepare for an influenza pandemic to decrease morbidity, mortality and societal disruption. Much of this planning takes place at the local level in regions, municipalities and health care institutions. The Canadian Paediatric Society urges paediatricians to be engaged in this planning in the settings where they work so that the needs of children and youth are considered and incorporated. This advocacy is likely to be most effective if it leads to solid planning now, rather than being voiced when the influenza pandemic arrives on our doorstep.

\section{REFERENCES}

1. Meltzer MI, Cox NJ, Fukuda K. The economic impact of pandemic influenza in the United States: Priorities for intervention. Emerg Infect Dis 1999;5:659-71.

2. Public Health Agency of Canada. Canadian Pandemic Influenza Plan. <http://www.phac-aspc.gc.ca/influenza/pandemicplan_e.html> (Version current at July 24, 2006).

3. Kilbourne ED. Influenza pandemics of the 20th century. Emerg Infect Dis 2006;12:9-14.

4. Webster RG, Guan Y, Poon L, et al. The spread of the H5N1 bird flu epidemic in Asia in 2004. Arch Virol Suppl 2005:117-29.

5. Tam T, Sciberras J, Mullington B, King A. Fortune favours the prepared mind: A national perspective on pandemic preparedness. Can J Public Health 2005;96:406-8.

6. Public Safety and Emergency Preparedness Canada. Keeping Canadians Safe. <http://www.psepc-sppcc.gc.ca/prg/em/gds/genprepen.asp $>$ (Version current at July 24, 2006).

7. World Health Organization. Epidemic and Pandemic Alert and Response (EPR). Current WHO phase of pandemic alert. <http://www.who.int/csr/disease/avian_influenza/phase/en/index.html> (Version current at July 24, 2006).

\section{RECOMMENDED READING}

- Government of Canada. Pandemic Influenza. $<$ http://www.influenza.gc.ca/> (Version current at July 24, 2006).

\section{INFECTIOUS DISEASES AND IMMUNIZATION COMMITTEE}

Members: Drs Simon Richard Dobson, BC's Children's Hospital, Vancouver, British Columbia; Joanne Embree, The University of Manitoba, Winnipeg, Manitoba (chair); Joanne Langley, IWK Health Centre, Halifax, Nova Scotia; Dorothy Moore, The Montreal Children's Hospital, Montreal, Quebec; Gary Pekeles, The Montreal Children's Hospital, Montreal, Quebec (board representative); Élisabeth Rousseau-Harsany, Sainte-Justine UHC, Montreal, Quebec (board representative); Lindy Samson, Children's Hospital of Eastern Ontario, Ottawa, Ontario

Consultant: Dr Noni MacDonald, Department of Pediatrics, IWK Health Centre, Halifax, Nova Scotia

Liaisons: Drs Upton Allen, The Hospital for Sick Children, Toronto, Ontario (Canadian Pediatric AIDS Research Group); Scott Halperin, IWK Health Centre, Halifax, Nova Scotia (IMPACT); Monica Naus, BC Centre for Disease Control, Vancouver, British Columbia (Health Canada, National Advisory Committee on Immunization); Larry Pickering, Centers for Disease Control and Prevention, Atlanta, Georgia, USA (American Academy of Pediatrics, Committee on Infectious Diseases)

Principal author: Dr Joanne Langley, IWK Health Centre, Halifax, Nova Scotia

The recommendations in this statement do not indicate an exclusive course of treatment or procedure to be followed. Variations, taking into account individual circumstances, may be appropriate. Internet addresses are current at time of publication. This article will also appear in an upcoming issue of Can J Infect Dis Med Microbiol 2006. 


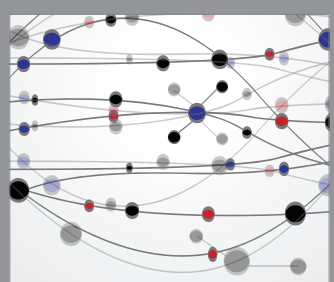

The Scientific World Journal
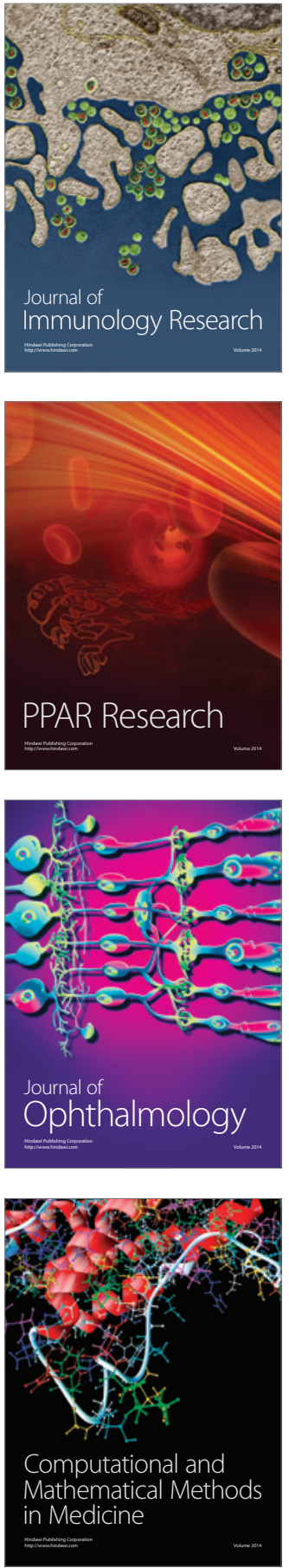

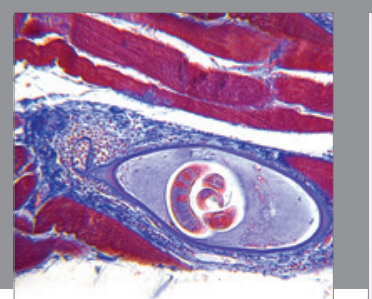

Gastroenterology Research and Practice

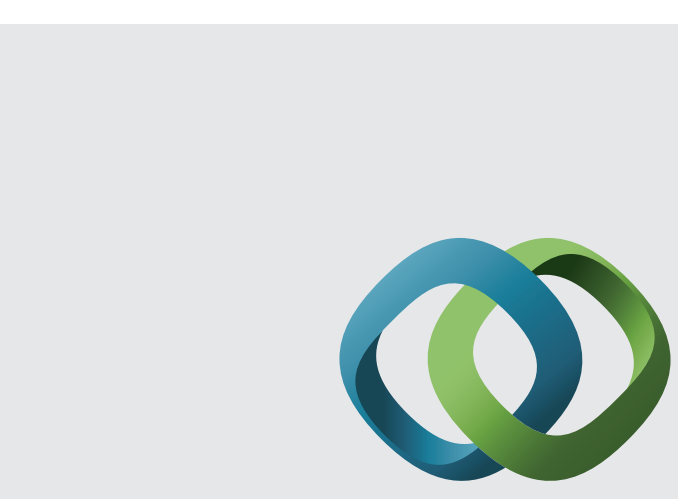

\section{Hindawi}

Submit your manuscripts at

http://www.hindawi.com
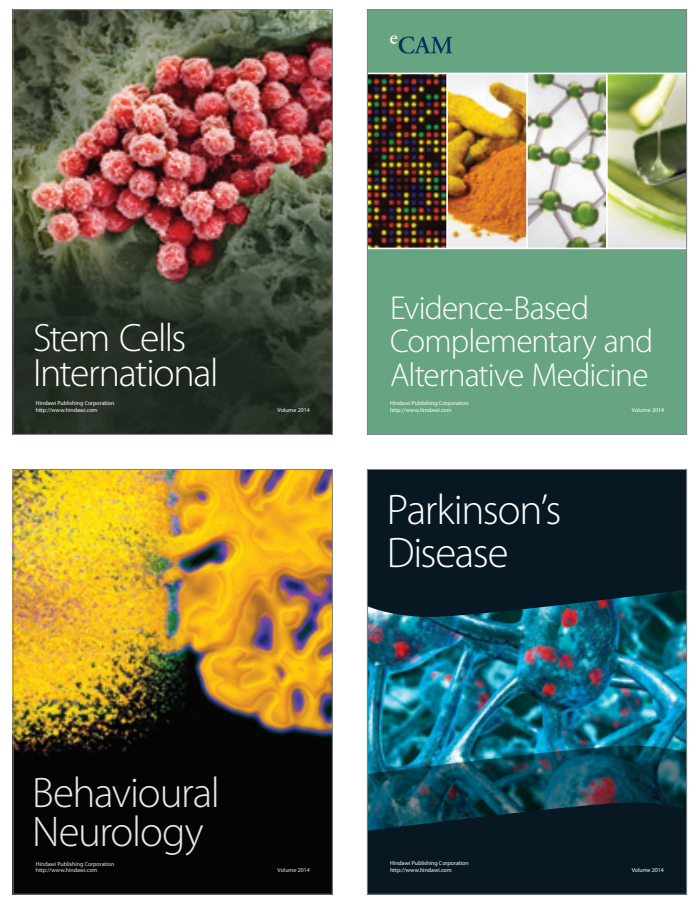
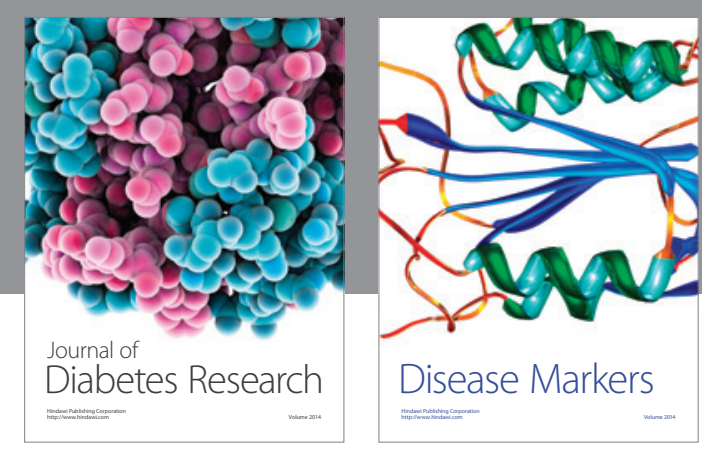

Disease Markers
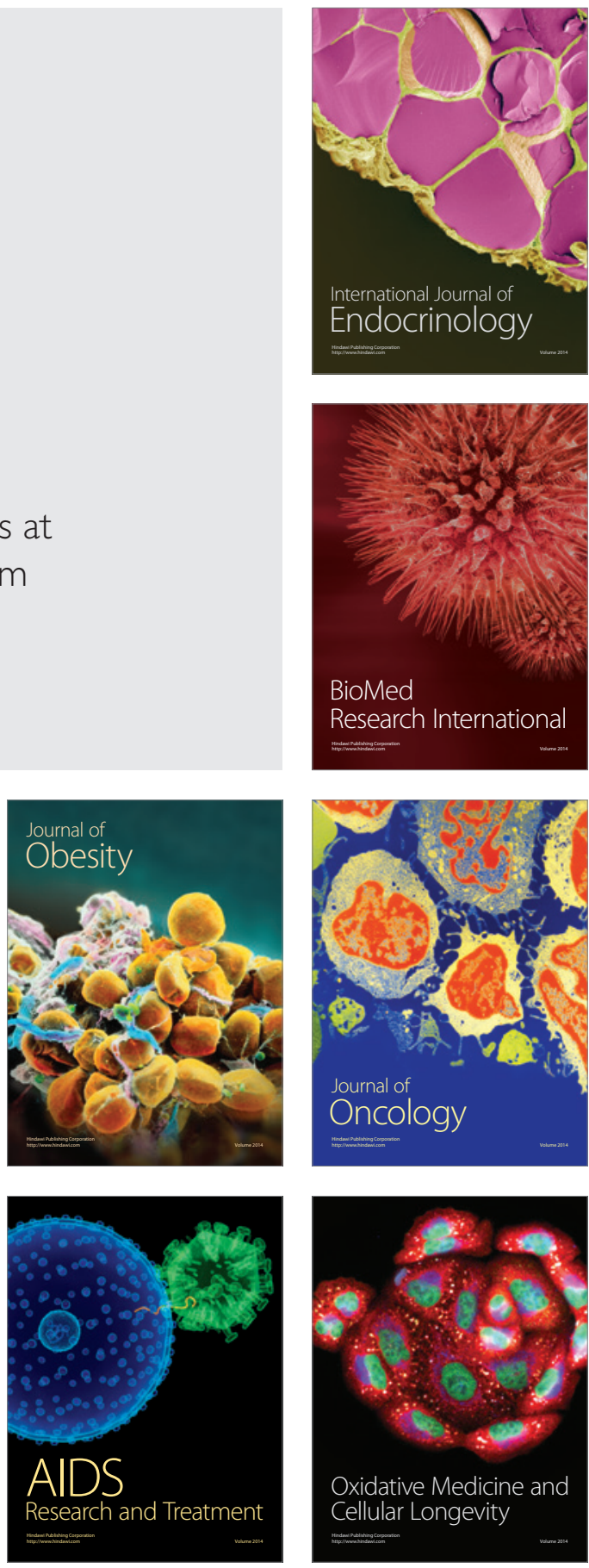